\title{
Decadal variability of the Elbe River streamflow
}

\author{
M. Ionita, ${ }^{\mathrm{a} *} \mathrm{~N} . \mathrm{Rimbu}^{\mathrm{a}}{ }^{\mathrm{b}}$ and G. Lohmann ${ }^{\mathrm{a}}$ \\ a Alfred Wegener Institute for Polar and Marine Research, Bremerhaven, Germany \\ b Climed Norad, Bucharest, Romania
}

\begin{abstract}
The decadal variability ( $>7$ years) of annual Elbe River flow in connection with large-scale atmospheric circulation is analysed for the period 1902-2002. The relationship with temperature over land (TT) and global sea surface temperature (SST) and atmospheric circulation over the Northern Hemisphere is investigated.

High anomalies of the river flow are associated with a tripole-like pattern in the North Atlantic and with negative SST anomalies in the central North Pacific and positive anomalies in the eastern and central tropical Pacific. The pattern identified in the sea level pressure (SLP) resembles the negative phase of the Arctic Oscillation pattern.

Two distinct decadal time components of approximately 12-13 years and 20 years in the time series were identified by using the Singular Spectral Analysis. To isolate the main frequencies identified by the Singular Spectrum Analysis (SSA) and to analyse the connection between the decadal components and Elbe River streamflow, we have applied a band pass filter to the SST field, to be able to suppress all the variance outside the prescribed windows. Copyright (C) 2009 Royal Meteorological Society
\end{abstract}

KEY WORDS climate variability; river streamflow; teleconnection patterns; spectral analysis

Received 19 December 2007; Revised 22 October 2009; Accepted 24 October 2009

\section{Introduction}

Water is a vital resource for human as well as the natural ecosystems. The availability of water is greatly influenced by climate conditions that vary on seasonal, interannual and decadal time scales. Characterization of hydrological variability on climate timescales and identification of connections to climate forcings provide potential improvement for hydrological forecasts when the climate forcings are predictable or slowly evolving (Croley and Luukkonen, 2003; Souza and Lall, 2003). Evidence from long hydrological records shows that periods with anomalous hydrological behavior (Arnell et al., 1993) are associated with persistent climate anomalies.

Two of the most important phenomena that influence streamflow variability are the North Atlantic Oscillation (NAO) and El Niño - Southern Oscillation (ENSO) (Dettinger and Diaz, 2000; Cullen et al., 2002). The indices of these large-scale climatic patterns are used as predictors for seasonal streamflow anomalies over Europe (Trigo et al., 2004; Rimbu et al., 2005). NAO consists of a north-south dipole of anomalies, with one centre located over Greenland and the other centre of opposite sign spanning the central latitudes of the North Atlantic between $35^{\circ} \mathrm{N}$ and $40^{\circ} \mathrm{N}$. The positive phase of the NAO reflects below-normal pressure anomalies across the high latitudes of the North Atlantic and above-normal pressure anomalies over the central North Atlantic, the eastern United States and western Europe.

* Correspondence to: M. Ionita, Alfred Wegener Institute, Bussestrasse 24, D-27570 Bremerhaven, Germany. E-mail: Monica.Ionita@awi.de
Interannual to decadal variability of the atmosphere over the North Atlantic region is mainly influenced by NAO teleconnection pattern (Bjerkens, 1964; Hurrell, 1995). Different studies focused on the influence of NAO on different climatic elements at different time scales, form interannual to decadal, show that NAO is responsible for generating systematic, large-amplitude patterns in the anomalies of temperature, precipitation, wind speed, latent and sensible heat flux, and hence Sea Surface Temperature SST, over much of the extra-tropical North Atlantic (van Loon and Rogers, 1978; Kushnir, 1994; Hurrell and van Loon, 1997).

Correlations with hydrological data have shown that, when NAO index is high, river flow is above average in northern Europe and below average in southern Europe (Shorthouse and Arnell, 1997; Dettinger and Diaz, 2000). Because river flows depend mainly on precipitation, it is evident that there is a strong connection between precipitation anomalies associated with extreme phase of NAO and river flow regimes in Europe. On decadal timescales there are strong parallels between North Pacific temperatures and NAO that reflect much coherence of the Northern Hemisphere climate (e.g. Livezey and Smith 1999). Rimbu et al. (2002) found a strong influence of the global SST on the Danube River flow, at decadal scale.

In the tropical Atlantic a cross-equatorial dipolar SST anomaly pattern with a period of 12-13 years has been identified, together with a 9-10 year period over the tropical North Atlantic (Allen and Smith, 1996; Mehta, 1998). River flow anomalies may be related to some 
of the same climatic oscillations that underlie those in SST.

This paper has two main goals: (1) to investigate the connection between Elbe River flow and temperature over land (TT), global SST and large-scale atmospheric circulation at decadal time scales and (2) to examine the spectra of Elbe River streamflow in order to explore the existence of statistically significant oscillatory components and to relate this components to variations in SST. Both spatial and temporal patterns associated with decadal variability of Elbe flow are discussed in connection with the dominant modes of decadal variability. It is important to study the connection between the climate variability and hydrological regime, in order to understand the physical mechanisms that drive hydrological variability. Long-term variability may be of significant importance for the managers of water resources systems for whom the ability to forecast reservoir inflows is highly desirable.

The paper is organized as follows. After the introduction a description of the data sets used in this study and some general characteristics of Elbe River basin are given. The decadal variability of Elbe River in connection with TT, SST and sea level pressure (SLP) is presented in Section 3. Section 4 presents the quasi-periodic patterns of Elbe streamflow variability as identified by the Singular Spectrum Analysis (SSA). In Section 5 the results of the band pass filter analysis are shown. A discussion and the main conclusions follow in Section 6.

\section{Data and methods}

The Elbe rises at an elevation of about $1400 \mathrm{~m}$ in the Giant Mountains on the north-west borders of the Czech Republic. It is approximately $1100 \mathrm{~km}$ long and covers a catchment area of about $150000 \mathrm{~km}^{2}$ and is inhabited by 25 million people. It covers the Czech Republic and Germany and discharges into the German Bight, North Sea (Figure 1, Potsdam Institute for Climate Impact Research and River Basin Community Elbe). The monthly time series of Elbe discharge, used in this paper, were recorded at Neu Darchau $\left(53^{\circ} 14^{\prime} \mathrm{N}, 10^{\circ} 53^{\prime} \mathrm{E}\right)$, which is situated in the lower part of Elbe catchement

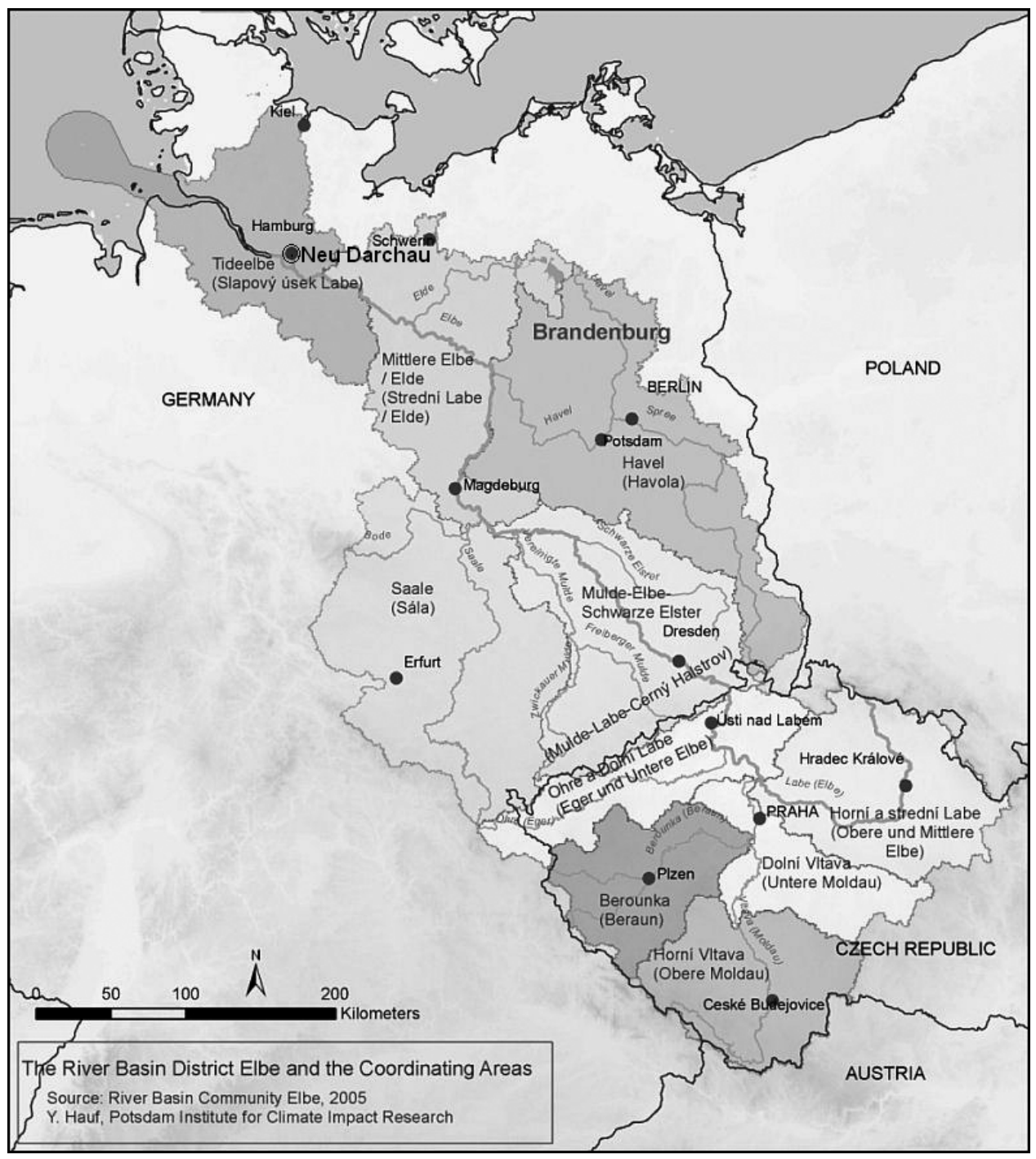

Figure 1. The Elbe catchment area (This picture is placed at the disposal of the Potsdam Institute for Climate Impact Research and River Basin Community Elbe). 


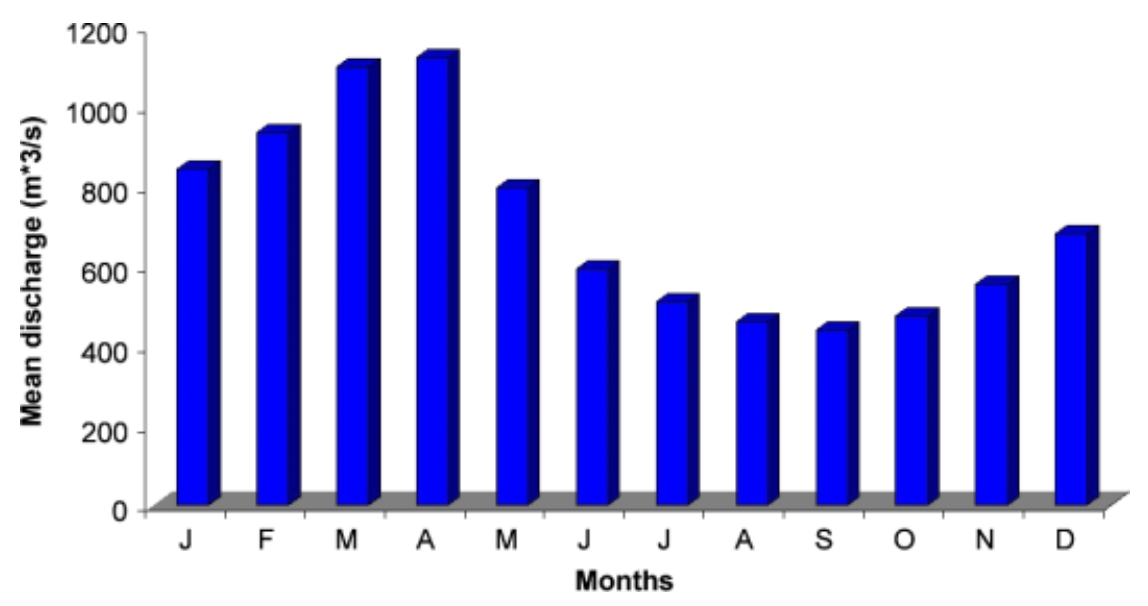

Figure 2. The annual cycle of Elbe River stramflow. Units are $\mathrm{m}^{3} \mathrm{~s}^{-1}$. This figure is available in colour online at www.interscience.wiley.com/ijoc

area (last gauging station) and they were provided by the German Federal Institute of Hydrology (BfG) in Koblenz, Germany. The annual cycle of Elbe River discharge is given in Figure 2. The hydrological discharge regime is characterized by a pronounced seasonal cycle, the rising limb of which is situated between January and April and the falling one between June and September, the highest values being recorded in April. These high discharge values recorded in the spring months may be related with the melting of the snow in the catchment area and the soil humidity.

The temperature data set was taken from CRU (Climatic Research Unit) TS2.1 data set (Mitchell et al., 2003). This data set has a $0.5 \times 0.5$ resolution and cover the period 1902-2002.

The global SST data, for the period 1902-2002, was extracted from an updated version of Kaplan data set (Kaplan et al., 1998). SST data set has a resolution of $5^{\circ} \times 5^{\circ}$

For the Northern Hemisphere atmospheric circulation we used an updated historical SLP data set $\left(5^{\circ} \times 5^{\circ}\right.$ grid box resolution) covering the period 1902-2002 (Trenberth and Paolino, 1980), with monthly resolution. We also used the time series of monthly Arctic Oscillation (AO) index (Thompson and Wallace, 2000). The Arctic Oscillation refers to opposing atmospheric pressure patterns in northern middle and high latitudes. In the positive phase, higher pressure at mid latitudes drives ocean storms farther north, and changes in the circulation pattern bring wetter weather to Alaska, Scotland and Scandinavia, as well as drier conditions to the western United States and the Mediterranean.

All the data sets were processed in the same way. First, the annual means (Elbe River flow) and seasonal winter (DJF) means (TT, SST, SLP) were calculated from monthly means. Then, annual anomalies with respect to the mean and normalized by standard deviation, estimated for the period 1902-2002, were produced. Both the annual and seasonal standardized anomalies were smoothed with a 7-year running mean filter to obtain the decadal component of the series. The 7-year running mean period chosen is somehow arbitrary, but is designed to fall near the low-frequency end of the spectrum associated with El Niño events and near the high-frequency end of the decadal climate variations of the Atlantic and North Pacific climate systems (Cayan et al., 1998; Dettinger et al., 2001). By applying this filter we exclude any cross-spectrum between Elbe River streamflow and El Niño.

The time series of annual means of Elbe's discharge recorded at Neu Darchau station during the period 1902-2002 is presented in Figure 3 (black line). The grey line represents the decadal component obtained by smoothing the series with a centred 7-year running mean.

To explain the decadal variability of the river streamflow in relation with large-scale atmospheric circulation we have constructed the composite maps between the standardized time series of Elbe River and TT, SST and SLP for the years of high $(>0.75)$, respectively low $(>-0.75)$ values of Elbe time series and we will show in the paper the maps corresponding to the difference between high and low. This threshold was chosen as a

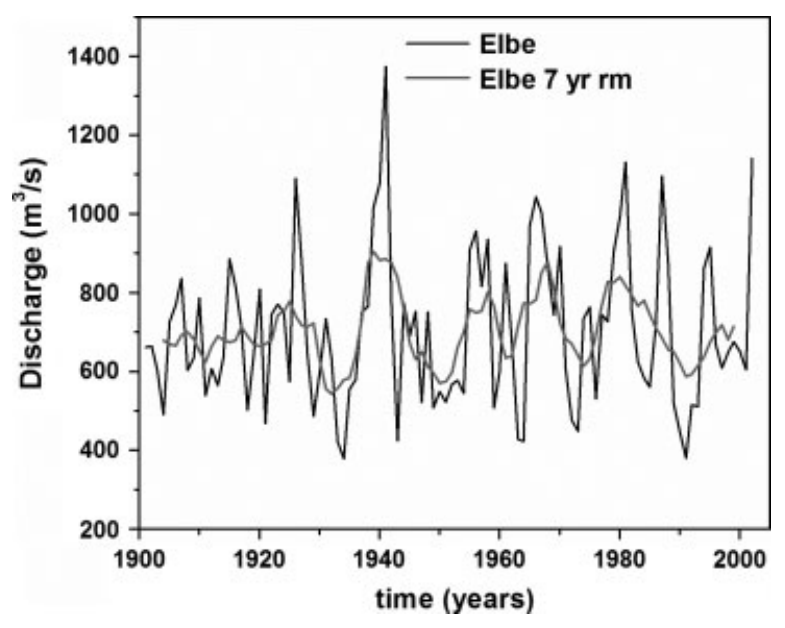

Figure 3. The time series of annual Elbe discharge (black line) recorded at Neu Darchau $\left(53^{\circ} 14^{\prime} \mathrm{N}, 10^{\circ} 53^{\prime} \mathrm{E}\right)$ for the period 1902-2002. Units are $\mathrm{m}^{3} \mathrm{~s}^{-1}$. The grey line represents the decadal component obtained by smoothing the series with a 7-year running mean. 
compromise between the strength of the climate anomalies associated with flow anomalies and the number of maps which satisfy this criteria. Further analysis has shown that the results are not sensitive to the exact threshold value used for our composite analysis.

In order to identify the dominant decadal components in the flow time series we used SSA. SSA is a powerful tool for time series analysis that can identify intermittent oscillation spells in short, noise time series (Vautard et al., 1992). The basic oscillations into which a time series decomposes are not functions of a prescribed, harmonic form. Instead, their shapes are determined from the time series itself. SSA has been successfully applied to many geophysical and climatologically time series to study and predict periodic activities (Ghil and Mo, 1991; Ghil and Vautard, 1991; Plaut and Vautard, 1994). SSA is based on an eigenvector decomposition of the autocorrelation matrix, making the effective 'filters' highly data adaptive. The calculations are made using the Toeplitz form of the autocorrelation matrix (Vautard et al., 1992). Spectral peaks are associated with oscillatory pairs of eigenvectors, from which the oscillatory part of the time series can be reconstructed.

A significance test of the oscillatory pairs can be made against red noise null hypothesis using a chi-squared test or a Mont Carlo method (Allen and Smith, 1996). In this paper we use the chi-squared method for all estimates of significance.

\section{Relation with global temperature and sea level pressure}

\subsection{Relationship with temperature over land}

In this section we analyse the relation between decadal variations of the Elbe River flow and the decadal variations of DJF TT over land (Figure 4). A strong outof-phase relationship is found between flow anomalies and winter TT over the Scandinavian region. Positive anomalies are also found with the TT over the northern part of Canada. This pattern in the TT field is similar to the spatial impact associated with the negative phase of the Arctic Oscillation (Thompson and Wallace, 1998). A strong negative anomaly of TT in winter, centred over the Scandinavian region, can trigger enhanced discharge in spring. This can be due to snow melting and by retaining the water in the soil during winter. However, from Figure 4 we can see that the streamflow anomalies are influenced not only by the AO-related TT anomalies but also by TT anomalies from other regions. This suggests that other phenomena, not necessarily related to $\mathrm{AO}$, also influence the streamflow anomalies. For example, the anomalies from the northern part of America could be connected with winter snow cover anomalies (Sobolowski et al., 2007).

\subsection{Relationship with global Sea Surface Temperature}

Several studies have established that large-scale SST fluctuations can be linked to atmospheric circulation that produces precipitation fluctuations (Dai et al., 1997; Latif et al., 2000). Rajagopalan et al. (1998) found evidence of significant coherence at decadal time scale between tropical South Atlantic SST and NAO, with warm SSTs associated with the positive phase of NAO.

The composite map (high-low) between annual flow and annual SST is shown in Figure 5. Positive anomalies of river flow are associated with negative SST anomalies in the central North Pacific and positive anomalies in the eastern and central tropical Pacific. This pattern resembles the SST pattern associated with the Pacific Decadal Oscillation (PDO) (Mantua et al., 1997). This result is compatible with the correlations between North

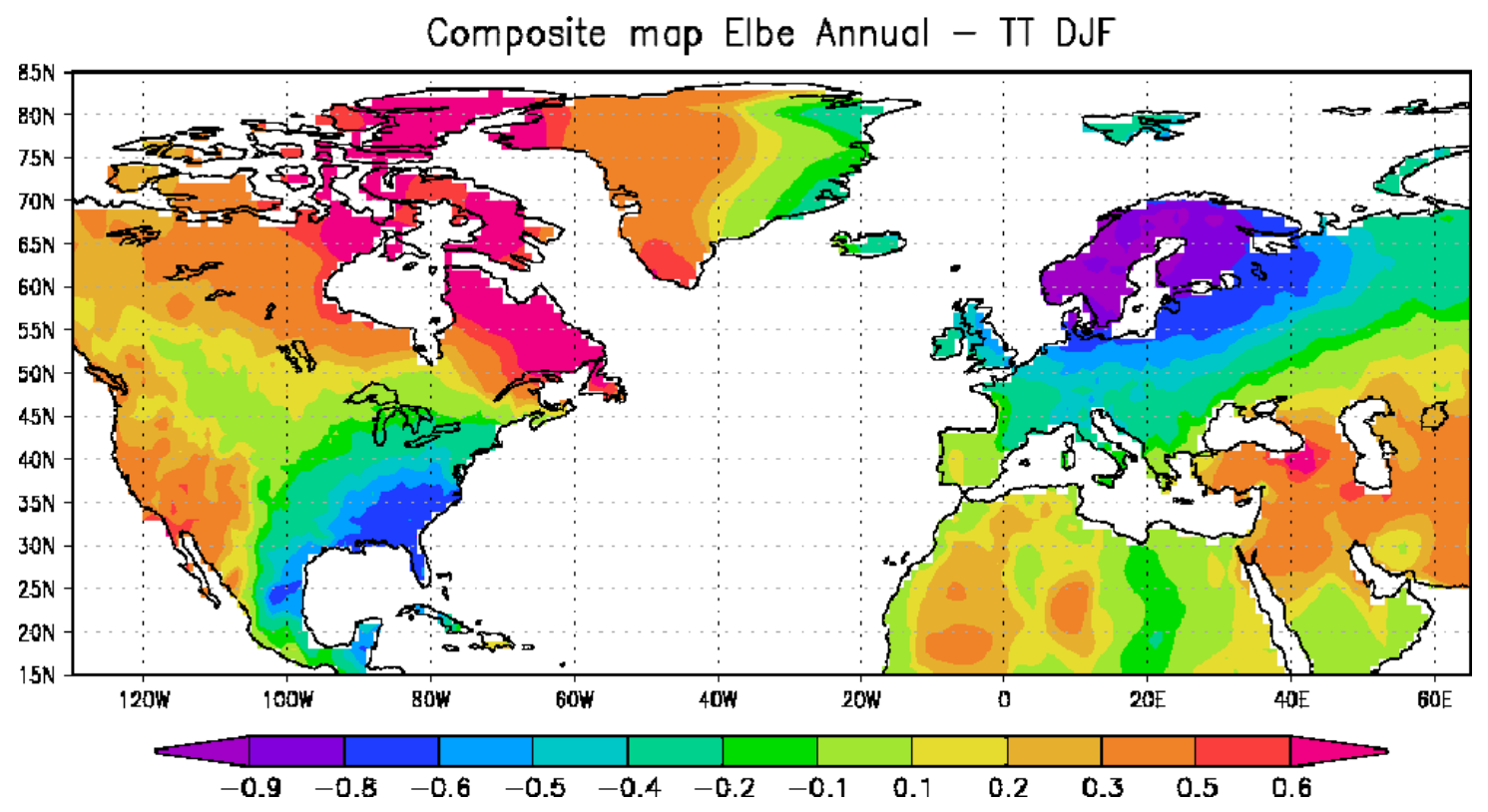

Figure 4. The composite map (high-low) between the time series of the decadal component of annual Elbe River flow and winter TT. This figure is available in colour online at www.interscience.wiley.com/ijoc 


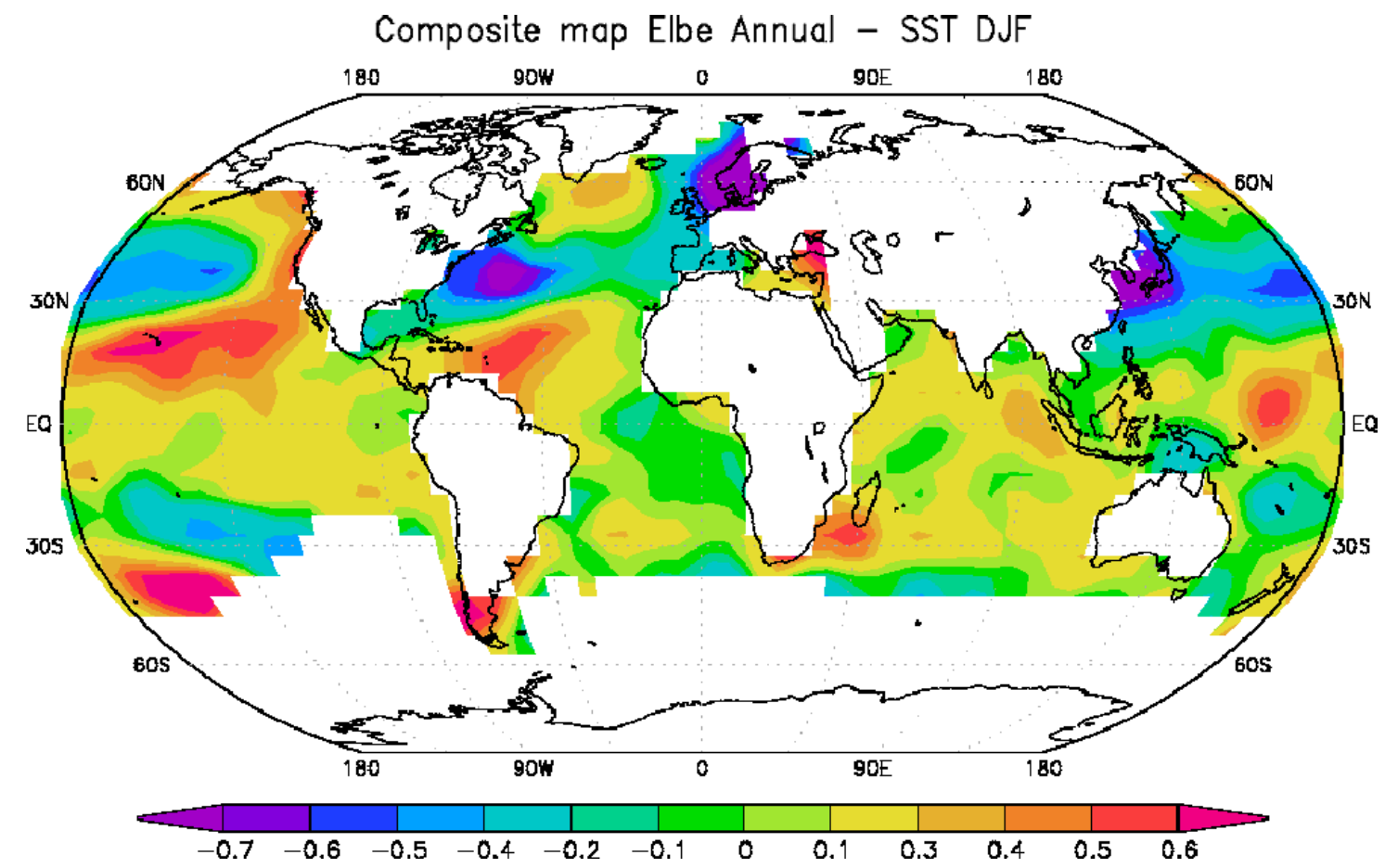

Figure 5. The composite map (high-low) between the time series of the decadal component of annual Elbe River flow and winter SST. This figure is available in colour online at www.interscience.wiley.com/ijoc

Pacific SSTs and river flows over North America, tropical Africa, centre and Southern Europe identified by Dettinger and Diaz (2000) and Danube River (Rimbu et al., 2002). High flow anomalies are also associated with a tripole-like pattern in the North Atlantic region similar to the pattern identified also by other authors (e.g. Hurrell, 1995; Desser and Blackmon, 1993). This pattern has been found to have a quasi-decadal variation of about 12 years. The significant connection of this pattern to Elbe River flow at a similar time scale, as showed here, is consistent with these studies.

\subsection{Connections with Northern Hemisphere SLP}

The composite map (high-low) between the time series of the Elbe River flow and SLP (Figure 6(a)) is consistent with the patterns identified in the SST field. This pattern resembles the AO pattern, but with the Pacific centre shifted toward north. Based on this pattern we defined four SLP indexes by averaging the normalized anomalies from the centres defined in Table I (first column). An Empirical Orthogonal Function (EOF) analysis was then applied to these four indexes. The first EOF explains $57 \%$ of the total variance. The weight of each loading is given in Table I (second column). The first principal component (PC1) associated to the first EOF is presented Figure 6(b), together with the Elbe flow and $\mathrm{AO}$ index. The correlation coefficient between PC1 and flow is $r=-0.7$, which is higher than the correlation between flow and AO index $(r=-0.55)$. This may be due to the fact that the pattern identified in Figure 7(a) might be the result of a superposition of different decadal modes of variability, like PDO or AO.

\section{Spectral analysis}

In order to identify the dominant decadal components in the annual flow time series we used SSA with a 40 years window length. Repeated SSAs with different window lengths show that the basic features of the identified time components remain stable and therefore are independent of the window length. For example, the structure of the eigenvalue spectrum (Figure 7(a)) and the approximate periods and amplitudes of the identified time components remain unchanged. Spectral peaks are associated with oscillatory pairs of eigenvectors, from which the oscillatory part of the time series can be reconstructed. A significant test of the oscillatory pairs can be made against a red noise null hypothesis using a chi-squared test or a Monte Carlo method (Allen and Smith, 1996). We used the chi-squared test for all estimates of the significance.

Using a lag window of $\mathrm{M}=40$ years, the two leading SSA eigenmodes (Figure 7(b)) form an oscillatory pair with a dominant period of approximately 20 years, which accounts for $40 \%$ of the total variance of the time series. Using the chi-squared test, the 20 years SSA pair is statistically significant against a red noise null hypothesis at $95 \%$ level. A similar pattern, which is characterized by a 20-25 years time scale, was identified by Dima et al. (2001b), who presented observational evidence of a quasi-bidecadal mode which may be generated from a linear interaction between phenomena originating in the Pacific and Atlantic basin. They also show that an AOlike structure, resulting from inter-ocean interactions, is associated with this quasi-bidecadal mode. 
(a) Composite map Elbe Annual - SLP DJF
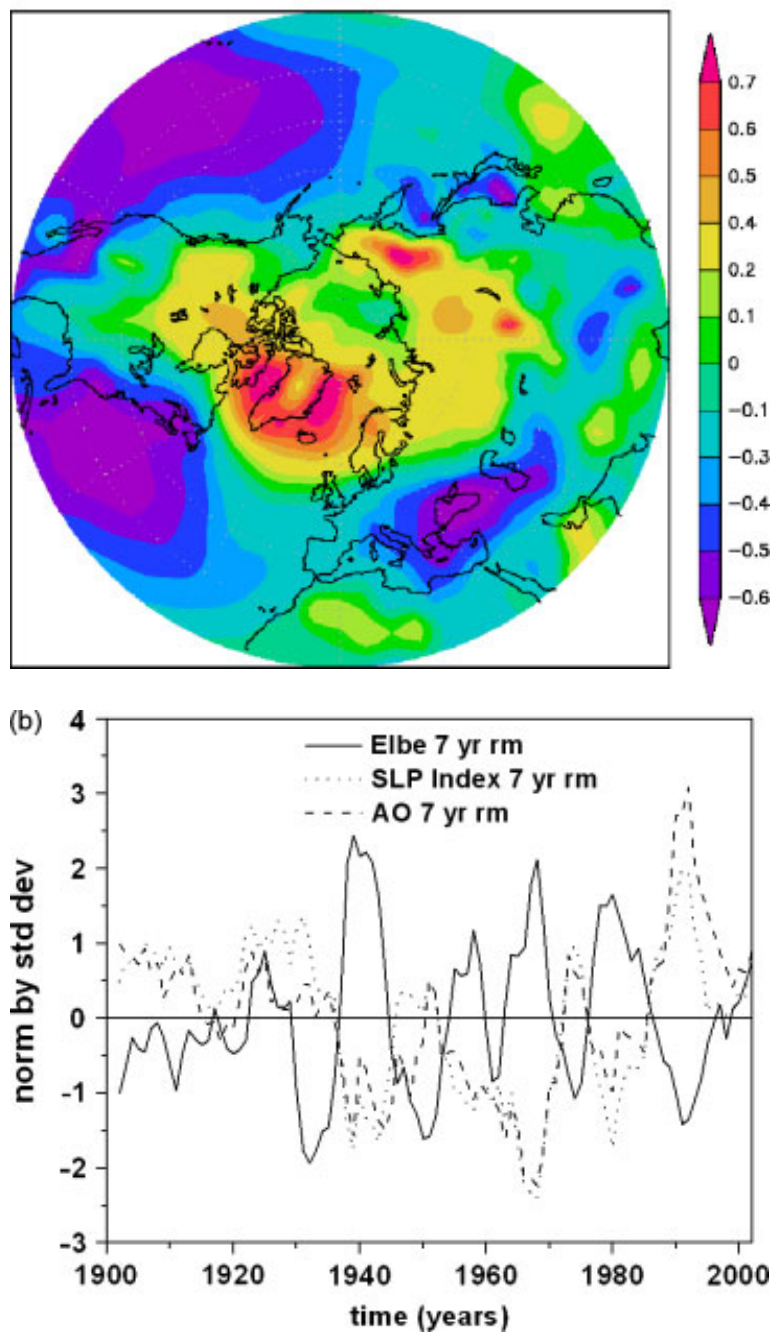

Figure 6. (a) The composite map between (high-low) the time series of the decadal component of annual Elbe River flow and winter SLP and (b) The time series of normalized anomalies of Elbe River flow (black line) and SLP index (grey line). Both time series were normalized and smoothed with a 7-year running mean. This figure is available in colour online at www.interscience.wiley.com/ijoc

The third and fourth leading SSA eigenmodes (Figure 7(c)) form an oscillatory pair with a dominant period of approximately 12 years and account for $32 \%$ of the total variance of the time series. The 12 years SSA pair is also statistically significant against a red noise null hypothesis at $95 \%$ level. Desser and Blackmon presented evidence for a quasi-decadal cycle in the North Atlantic. This mode is characterized by latitudinal bands of alternating polarities that extent from tropics to the North Atlantic (Desser and Blackmon, 1993; Dima et al., 2001a) and is consistent with the SST pattern from Figure 5.

\section{Band pass filter analysis}

In order to isolate the main frequencies identified by the SSA analysis, we have applied a band pass filter to SST field, to be able to suppress all the variance outside the prescribed windows (von Storch and Zwiers, 1999).
Table I. The coordinates (latitude, longitude) of the winter SLP indices used in this study (first column) and the weights of the loadings corresponding to EOF1 for each index (second column).

\begin{tabular}{lc}
\hline Latitude-longitude & Weights of the loadings \\
\hline $110^{\circ} \mathrm{W}-140^{\circ} \mathrm{W}, 30^{\circ} \mathrm{N}-50^{\circ} \mathrm{N}$ & 0.39 \\
$40^{\circ} \mathrm{W}-70^{\circ} \mathrm{W}, 30^{\circ} \mathrm{N}-45^{\circ} \mathrm{N}$ & 0.54 \\
$20^{\circ} \mathrm{E}-40^{\circ} \mathrm{E}, 40^{\circ} \mathrm{N}-50^{\circ} \mathrm{N}$ & 0.48 \\
$70^{\circ} \mathrm{W}-5^{\circ} \mathrm{E}, 60^{\circ} \mathrm{N}-80^{\circ} \mathrm{N}$ & -0.57 \\
\hline
\end{tabular}

The filtering was applied for the two main frequencies identified in the previous section: 12 years (F12, from now on) and 20 years (F20, from now on). Thus, we performed the filter for wave numbers between 6 and 9 for F12 and 4 and 5 for F20, respectively. These wave numbers represent periods of 11-15 years and 17-25 years, respectively, for our time series length of 101 years.

The second approach was to apply an EOF analysis to the SST filtered data set. For F12, the EOF analysis was applied just for the Atlantic region, since the 12 years periodicity is specific to this area. For F20, the EOF analysis was performed on global scale.

The first EOF (Figure 8(a)) of band pass-filtered SST in the range of $11-15$ years explains $71.54 \%$ of the total variance. EOF1 is characterized by a tripole-like pattern in the Atlantic region. This pattern resembles the composite map between Elbe discharge and global SST identified in Figure 5. There is significant observational evidence for the SST variability on 10-14 years in various parts of the Atlantic Ocean, which are supposed to be part of a coherent pan-Atlantic decadal oscillation (Desser and Blackmon, 1993; Dima and Lohmann, 2004).

In order to further prove that the F12 mode and Elbe River streamflow co-vary, we relate (Figure 8(b)) the reconstructed time series corresponding to the SSA components 3 and 4, identified in previous section, and the PC1 corresponding to the first EOF. The two time series are in an out-of-phase relationship, showing a good agreement for almost the whole period analysed, with some exceptions at the beginning of the interval.

The first EOF of the band pass-filtered SST (Figure 9 (a)), in the range of $17-25$ years, explains $66.71 \%$ of the total variance. This pattern resembles the PDO pattern described by Kaplan et al. (2000) and others (Mantua et al., 1997; Tourre et al., 2001). EOF1 is characterized by a large area of positive anomalies in the eastern equatorial Pacific that extends up to the North a south of American coasts. There is also the typical cold water tongue in the west Pacific.

The reconstructed time series corresponding to the SSA components 1 and 2 and $\mathrm{PC} 1$, corresponding to EOF1-F20, are strongly correlated $(r=0.86)$ (Figure 9(b)). There is a strong relationship between the two time series and the phase is identical for the whole period analysed. 

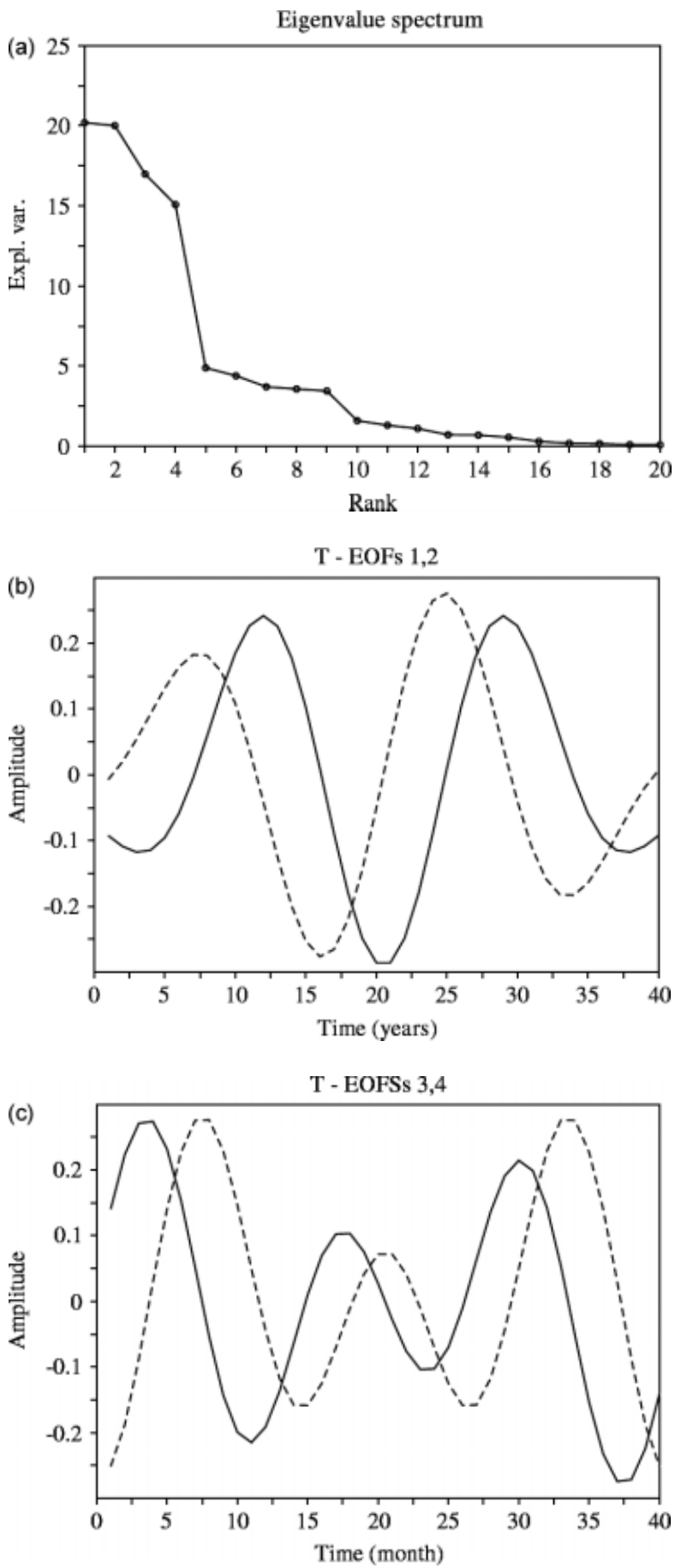

Figure 7. (a) Eigenvalues derived from SSA of the annual Elbe River flow; (b) EOFs 1 and 2, explaining $40 \%$ of the total variance; (c) EOFs 3 and 4 , explaining $32 \%$ of the total variance. The time-EOFs of each pair are in quadrature, indicating that each of the two pairs is associated with a quasi-periodic component.

\section{Discussion and conclusions}

In this study we have investigated the decadal variability of Elbe River flow and its connection with over land and SST and atmospheric circulation over the Northern Hemisphere, for the period 1902-2002.

On decadal time scale, high flow anomalies are strongly correlated with winter TT over land. There is an out-of-phase relationship between Elbe flow and TT (a) EOF 1 SST DJF Bandpass-filter 11-15 Years Expl. Var. 71.54\%
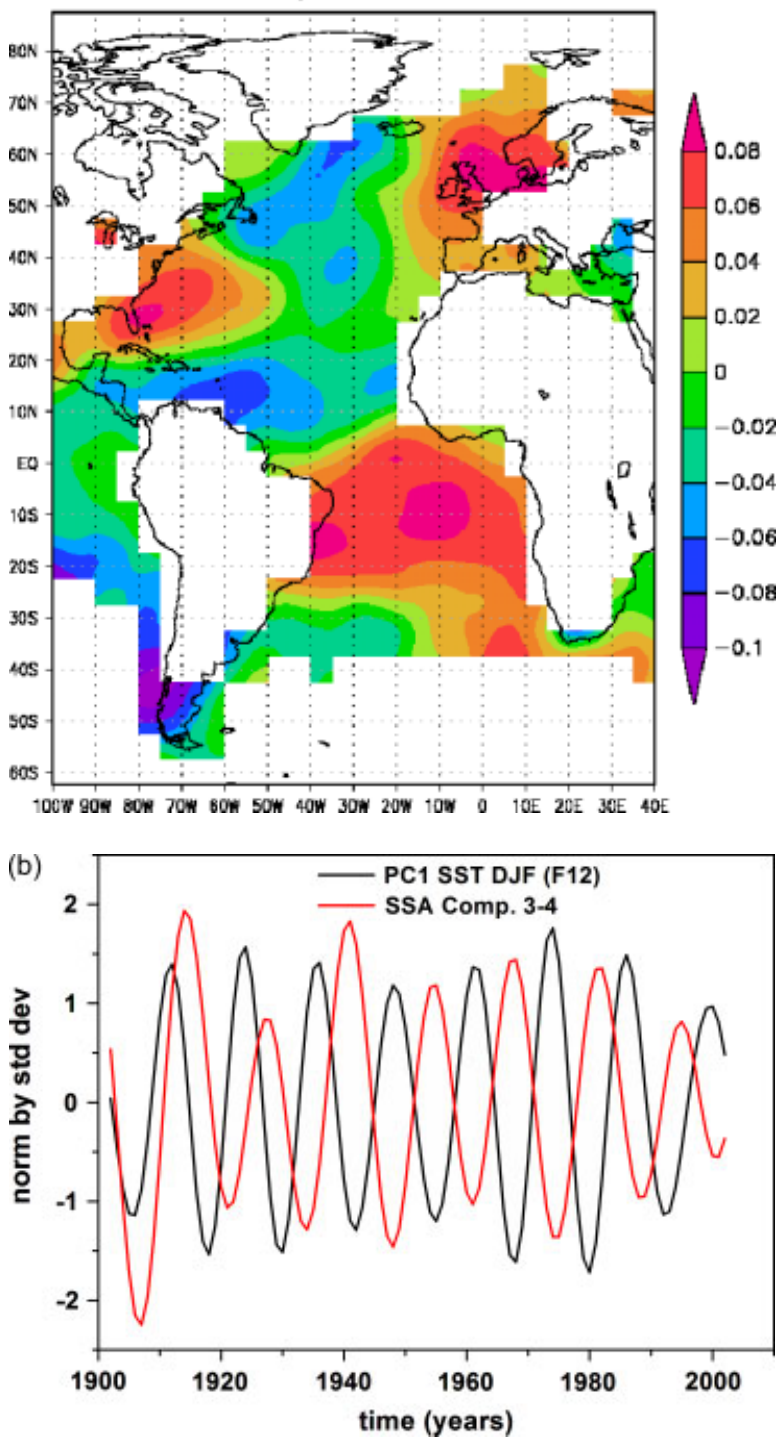

Figure 8. (a) EOF1 pattern of the band pass-filtered (F12) SST anomalies and (b) PC1 (F12) of band pass-filtered SST (black line) and the reconstructed time series corresponding to the SSA components 3 and 4 (red line). This figure is available in colour online at www.interscience.wiley.com/ijoc

over Scandinavian region. High positive correlation is also found with the TT over the northern part of Canada. This pattern in the TT field is similar to the negative phase of the Arctic Oscillation. Similar results have also been found on seasonal time scale for Elbe River streamflow (Ionita et al., 2008).

The composite map between Elbe River flow and SSTs shows that high flow anomalies tend to be associated with low SST anomalies in the central North Pacific and high SST anomalies in the eastern and central tropical Pacific and with a tripole-like pattern in the Atlantic basin. The corresponding SLP composite map emphasizes a tripole-like pattern of SLP anomalies, similar to that characterizing the negative phase of the AO pattern.

The strong relationship of flow with the SST from Pacific and Atlantic basin can be explained via the 
(a) EOF1 SST DJF Bondposs-filter 17-25 Years Expl, Vor. $66.71 \%$

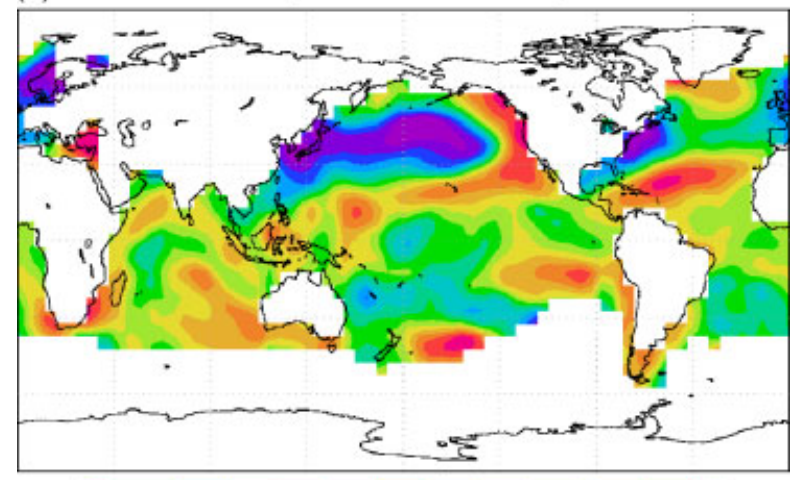

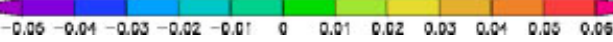

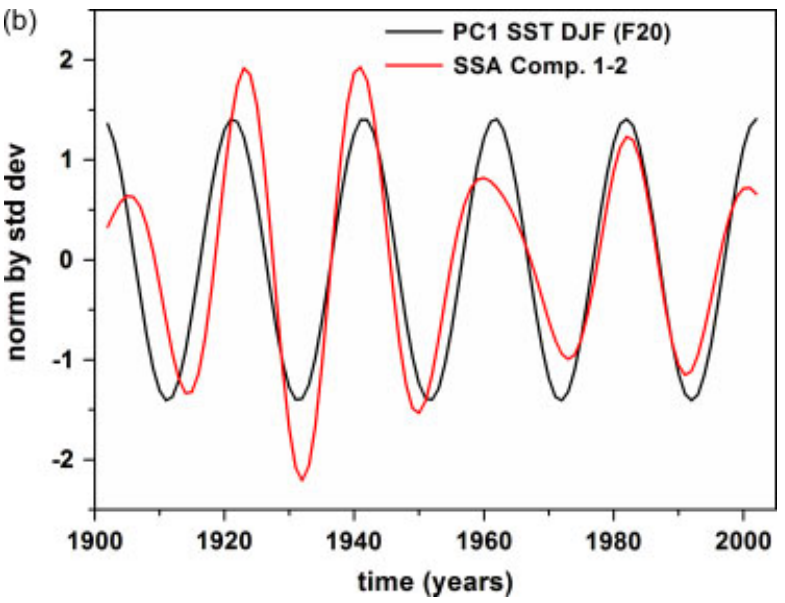

Figure 9. (a) EOF1 pattern of the band pass-filtered (F20) SST anomalies and (b) PC1 (F20) of band pass-filtered SST (black line) and the reconstructed time series corresponding to the SSA components 1 and 2 (red line). This figure is available in colour online at www.interscience.wiley.com/ijoc

mechanism proposed by Dima et al. (2001a). They argue that there is an interaction between phenomenon originating in the Tropical Pacific, like ENSO, and the Atlantic basin, like the Atlantic quasi-decadal mode. The result of this interaction is a coherent mode at global scale. The 20-year oscillation over the North Pacific is suspected to have a source region over the Pacific Ocean (Trenberth, 1990; Graham, 1994; Dima et al., 2001b) and is related to the PDO.

The quasi-decadal variation revealed in Atlantic SSTs is consistent with many previous studies. In addition to the Atlantic Ocean, this mode of variation has been observed in global surface air temperature (Mann and Park, 1994), US stream flow (Guetter and Georgakakos, 1993), Great Basin precipitation (Eischeid et al., 1985), and the volume of the Great Salt Lake (Mann et al., 1995).

In summary, we conclude that the decadal variability of Elbe River flow is driven by climate interactions at nearly global scale. These results have implications for predicting the evolution of Elbe River discharge on decadal time scales.

\section{References}

Allen MR, Smith LA. 1996. Monte Carlo SSA: detecting irregular oscillations in the presence of coloured noise. International Journal of Climatology 9: 3373-3404.

Arnell NW, Krasovskaia I, Gottschalk L. 1993. River flow regimes in Europe. In Flow Regimes from International Experimental and Network Data (FRIEND): Hydrological Studies, vol. 1, Gustard A (ed). Institute of Hydrology: Wallingford, Oxfordshire, UK: 112-121.

Bjerknes J. 1964. Atlantic air-sea interactions. Advances in Geophysics 10: $1-82$.

Cayan D, Dettinger MD, Diaz HF, Graham N. 1998. Decadal variability of precipitation over western United States. Journal of Climate 12: 2881-2893.

Croley TE II, Luukkonen CL. 2003. Potential effects of climate change on ground water in Lansing, Michigan. Journal of the American Water Resources Association 39: 149-163.

Cullen HM, Kaplan A, Arkin P, DeMenocal PB. 2002. Impact of the North Atlantic Oscillation on Middle Eastern climate and streamflow. Climatic Change 55: 315-338.

Dai AG, Fung IY, DelGenio AD. 1997. Surface observed global land precipitation variations during 1900-1988. Journal of Climate 10: $2943-2962$.

Desser C, Blackmon ML. 1993. Surface climate variations over the North Atlantic Ocean during winter: 1900-1989. Journal of Climate 6: $1743-1953$.

Dettinger MD, Diaz HF. 2000. Global characteristics of stream flow seasonality and variability. Journal of Hydrometeorology $\mathbf{1}$ 289-310.

Dettinger MD, Battisti DS, Garreaud RD, McCabe GJ, Bitz CM. 2001. Interhemispheric effects of interannual and decadal ENSOlike climate variations on the Americas, in V. Markgraf (ed.) Interhemispheric climate linkages: Present and Past Climates their Societal Effects: Academic Press, 1-16.

Dima M, Rimbu N, Stefan S, Dima I. 2001a. Quasi-decadal variability in the Atlantic Basin involving tropics-midlatitudes and ocean-atmosphere interactions. Journal of Climate 14: 823-832.

Dima M, Stefan S, Dima V, Borsan D. 2001b. Interdecadal variability generated by interactions between Pacific and Atlantic Oceans Geophysical Research Letters 28: 4459-4461.

Dima M, Lohmann G. 2004. Fundamental and derived modes of climate variability. Application to biennial and interannual timescale. Tellus 56A: 229-249.

Eischeid IK, Bradley RS, Shao X. 1985. Secular climatic fluctuations in the Great Salt Lake basin. In Problems and Prospects for of Prediction Great Salt Lake Le6els, Kay P, Diaz HF (eds). Center for Public Affairs and Administration, University of Utah: Salt Lake City, UT: $111-122$.

Ghil M, Mo K. 1991. Intraseasonal oscillations in the global atmosphere. Part 1: Northern Hemisphere and tropics. Journal of Atmospheric Science 48: 752-779.

Ghil M, Vautard R. 1991. Interdecadal oscillations and the warming trend in global temperature time series. Nature 350: 324-327.

Graham NE. 1994. Decadal-scale climate variability in the 1970s and 1980s: observations and model results. Climate Dynamics 10: $135-159$.

Guetter AK, Georgakakos KP. 1993. River outflow of the conterminous United States, 1939-1988. Bulletin of the American Meteorological Society 74: 1873-1891.

Hurrell J. 1995. Decadal trends in the North Atlantic oscillation: regional temperatures and precipitation. Science 269: 676-679.

Hurrell JW, van Loon H. 1997. Decadal variations in climate associated with the North Atlantic oscillation. Climatic Change 36: 301-306.

Ionita M, Lohmann G, Rimbu N. 2008. Prediction of Elbe discharge based on stable teleconnections with winter global temperature and precipitation. Journal of Climate 21: 6215-6226, DOI:10.1175/2008JCLI2248.1.

Kaplan A, Cane MA, Kushnir Y, Clement AC, Blumenthal MB, Rajagopolan B. 1998. Analysis of global sea surface temperature 1856-1991. Journal of Geophysical Research 103: 567-589.

Kaplan A, Kushnir Y, Kane MA. 2000. Reduced space optimal interpolation of historical marine sea level pressure: 1854-1992. Journal of Climate 13(16): 2987-3002.

Kushnir Y. 1994. Interdecadal variations in the North Atlantic sea surface temperature and associated atmospheric conditions. Journal of Climate 7: 141-157. 
Latif M, Arpe K, Roeckner E. 2000. Oceanic control of decadal North Atlantic sea level pressure variability in winter. Geophysical Research Letters 27: 727-730.

Livezey RE, Smith TM. 1999. Covariability of aspects of North American climate with global sea surface temperatures on interannual to interdecadal timescales. Journal of Climate 12: 289-302.

van Loon H, Rogers JC. 1978. The seesaw in winter temperatures between Greenland and Northern Europe. Part I: general description. Monthly Weather Review 106: 296-310.

Mann ME, Park J. 1994. Global-scale modes of surface temperature variability on interannual to century timescales. Journal of Geophysical Research 99: 25819-25833.

Mann ME, Lall U, Saltzman B. 1995. Decadal-to-centennial-scale climate variability: insights into the rise and fall of the Great Salt Lake. Geophysical Research Letters 22: 937-940.

Mantua NJ, Hare SJ, Zhang Y, Wallace JM, Francis RC. 1997. A Pacific interdecadal climate oscillation with impacts on salmon production. Bulletin of the American Meteorological Society $\mathbf{7 8}$ $1069-1079$.

Mehta V. 1998. Variability of the tropical ocean surface temperatures at decadal-multidecadal timescales. Part I: the Atlantic Ocean. Journal of Climate 11: 2351-2375.

Mitchell TD, Carter TR, Jones PD, Hulme M, New M. 2003. A Comprehensive Set of High-resolution Grids of Monthly Climate for Europe and the Globe: The Observed Record (1901-2000) and 16 Scenarios (2001-2100). Tyndall Center Working Paper 55.

Plaut G, Vautard R. 1994. Spells of low-frequency oscillations and weather regimes in the Northern Hemisphere. Journal of Atmospheric Science 51: 210-236.

Rajagopalan B, Kushnir Y, Tourre YM. 1998. Observed decadal midlatitude and tropical Atlantic climate variability. Geophysical Research Letters 25: 3967-3970.

Rimbu N, Boroneant C, Buta C, Dima M. 2002. Decadal variability of the Danube river flow in the lower basin and its relation with the North Atlantic Oscillation. International Journal of Climatology 22 : $1169-1179$.

Rimbu N, Dima M, Lohmann G, Musat I. 2005. Seasonal prediction of Danube flow variability based on stable teleconnection with sea surface temperature. Geophysical Research Letters 32: L21704, DOI:10.1029/2005GL024241.
Shorthouse C, Arnell NW. 1997. Spatial and temporal variability in European river flows and the North Atlantic oscillation. In FRIEND'97 - Regional Hydrology: Concepts and Models for Sustainable Water Resource Management, Gustard A, Blazkova S, Brilly M, Demuth S, Dixon J, van Lanen H, Llasat C, Mkhandi S, Servat E (eds). IAHS: Walling Ford: 77-85, IAHS Publication No. 246.

Sobolowski S, Gong G, Ting M. 2007. Northern Hemisphere winter climate variability: response to North American snow cover anomalies and orography. Geophysical research letters 34: L16825, DOI:10.1029/2007GL030573.

Souza FA, Lall U. 2003. Seasonal to interannual ensemble streamflow forecasts for Ceara, Brazil: applications of a multivariate, semiparametric algorithm. Water Resources Research 39: 1307, DOI:10.1029/2002WR001373.

von Storch H, Zwiers F. 1999. Statistical Analysis in Climate Research, Cambridge University Press, ISBN 052145071 3, 494 pp.

Thompson DWJ, Wallace JM. 1998. The Arctic Oscillation signature in the wintertime geopotential height and temperature fields. Geophysical Research Letters 25: 1297-1300.

Thompson DWJ, Wallace JM. 2000. Annular modes in the extratropical circulation. Part I: month-to-month variability. Journal of Climate 13: $1000-1016$.

Tourre YM, Kushnir M, White WB. 2001. Patterns of coherent decadal and interdecadal climate signals in the Pacific basin during the 20th century. Geophysical Research Letters 28: 2069-2072.

Trenberth KE. 1990. Recent interdecadal climate changes observed in the Northern Hemisphere. Bulletin of the American Meteorological Society 71: 988-993.

Trenberth KE, Paolino DA. 1980. The Northern Hemisphere sea-level pressure data set: trends, errors and discontinuities. Monthly Weather Review 108: 855-872.

Trigo RM, Vazquez DP, Osborn TJ, Castro-Diez Y, Gamiz-Fortıs S, Esteban-Parra MJ. 2004. North Atlantic oscillation influence on precipitation, river flow and water resources in the Iberian peninsula. International Journal of Climatology 24: 925-944.

Vautard R, Yiou P, Ghil M. 1992. Singular-spectrum analysis: a toolkit for short, noisy chaotic signals. Physica D 58: 95-126. 